\title{
Phenotypic Characteristics of Strawberry related to Photo- physiological Parameters according to Temperature and Relative Humidity in a Greenhouse after Planting
}

Hyo Gil Choi ${ }^{1, *}$ and Nam Jun $\mathrm{Kang}^{2,3, *}$

${ }^{1}$ Department of Horticulture, Kongju National University, Yesan 32439, Korea

${ }^{2}$ Department of Horticulture, Gyeongsang National University, Jinju 52828, Korea

${ }^{3}$ Institute of Agriculture \& Life Science, Gyenongsang National University, JinJu 52828, Korea

*Corresponding author:

hg1208@kongju.ac.kr; Tel.: +82-41-330-1221 and k284077@gnu.ac.kr; Tel.: +82-55-772-1915

Abstract: The low relative humidity $(\mathrm{RH})$ levels in a greenhouse during the daytime in a strawberry (Fragaria
$\times$ ananassa Duch) cultivation period negatively affect the growth of strawberry related to photo-physiology. Therefore, this study was conducted to confirm an efficient RH management method by analyzing the phenotypic characteristics related to photo-physiology by controlling the $\mathrm{RH}$ in a greenhouse during the daytime with a fog system. Strawberry plants were grown respectively in a greenhouse affected by natural $\mathrm{RH}$ changes (control) and in a greenhouse with 40\% 50\% RH adjusted during the daytime using a fog system. In the greenhouse, with controlled RH, the temperature decreased, and the RH was higher in the initial growth stage of strawberry planting than the control. It was observed a significant increase in the survival rate of the strawberry plant, as well as the incidence of powdery mildew, was lowered. In addition, the photosynthetic rate and OJIP chlorophyll a fluorescence transients related to photosystem II efficiency of strawberry leaves were significantly higher in the fog treatment than in the control. In winter, during the day, the number of days on which the temperature dropped below $20^{\circ} \mathrm{C}$ has increased, the greenhouse temperature with controlled $\mathrm{RH}$ was lower due to the fog system. When the yield per strawberry plant in January and February was investigated, the control was higher than the RH treatment. Therefore, $\mathrm{RH}$ management using a fog system must be controlled at a level where a temperature range is adequate for plant growth, in which the efficient control of these parameters increases strawberry productivity.

Keywords- chlorophyll fluorescence, fog system, greenhouse, energy flux, OJIP, photosynthesis 


\section{Introduction}

Many horticultural crops are cultivated in a controllable greenhouse for optimal productivity, where typical environmental factors such as light, temperature, and carbon dioxide are controlled. In particular, air temperature affects plants' photosynthesis, photorespiration, and respiration, which induces positive or negative growth of plants [1]. It is known that controlling the cultivation temperature of horticultural crops from $18^{\circ} \mathrm{C}$ to $24^{\circ} \mathrm{C}$ in a greenhouse is advantageous for productivity $[2,3]$. Therefore, through air temperature management using energy, horticultural crops in the greenhouse maintain high productivity than open field crops. Relative humidity (RH), along with temperature, is one of the most important environmental factors in greenhouses influencing the physiological response and yield of various horticultural crops $[4,5]$. Especially, RH is highly related to the opening and closing of stomata, which affects the plants' photosynthesis. So, regulating $\mathrm{RH}$ is an important cultivation management method after planting or grafting horticulture crops grown in a greenhouse $[6,7]$, whereby the maintenance of an appropriate RH has a positive influence on the growth of horticultural crops [8,9]. Also, it has been reported that in various cultivation regions, differences in RH have a significant impact on the carbon fixation of rice crops grown in the open field [10].

Strawberry (Fragaria $\times$ ananassa Duch.) is a berry fruit, popular worldwide as sweet and fresh fruit and with potential health benefits [3]. In Korea, strawberries have the highest productivity among horticultural crops, with the produce of $\$ 1.3$ billion in 2015 [11]. In particular, over $83 \%$ of strawberries grown commercially in Korea are "Seolhyang" cultivar [12]. In this country, most strawberries are cultivated in greenhouses with a heating system, so they are planted in September and harvested from December to April of the following year. After planting strawberries in a greenhouse, the period between September to November is very important for initial management. However, during this initial management period, there is dry weather in Korea, which affects the greenhouse conditions where the RW is low and very dry. But after planting in a greenhouse, RH plays a major role in horticultural crop growth, being a significant environmental management factor [13]. In strawberry cultivation, it is observed that RH has a great influence on the physiological responses related to photosynthesis and promotes the development and growth of leaves [14, 15].

The chlorophyll $a$ fluorescence OJIP transient (OJIP) test is widely used to analyze the photophysiological response of horticultural crops under various environmental conditions [16, 17]. Several parameters of the OJIP test show a change in the pattern over time under extreme conditions, such as the process of plant cell death [18]. To confirm the plant growth condition of plants under various environmental regimes, photosynthetic parameters such as photosynthetic rate, stomatal conductance, and transpiration rate are also widely used to measure the photo-physiological response of horticulture crops to environmental 
changes [19]. OJIP and photosynthesis measurement methods also have the advantage analyze physiological phenomena non-destructively in plants.

Temperature and RH are very important environmental management factors for cultivating strawberries in a greenhouse, but it is not clear which of them is the priority management environmental factor. Therefore, this study was conducted in a greenhouse after planting strawberries, with RH and temperature management using a fog system, to determine the changes in the phenotypic characteristics such as OJIP and photosynthetic efficiency. Also, is proposed an environmental management algorithm that can control the temperature and RH more efficiently, in the cultivation of strawberries in a greenhouse, based on the analysis of the photosynthetic rate of strawberry leaves.

\section{Materials and Methods}

\subsection{Strawberry plant cultivation and materials}

The strawberry (Fragaria $\times$ ananassa Duch.) plants used in this experiment were three cultivars, "Seolhayng," "Kuemsil," and "Arihyang," bred in Korea. The strawberry seedlings were planted in a hydroponics bed system filled with a coco peat medium in greenhouses at Kongju National University, Korea. Two greenhouses were used to set different RH levels in this experiment (Figure 1). Immediately after strawberry planting, one greenhouse controlled $\mathrm{RH}$ at ranges of $40 \% \leq \mathrm{RH} \leq 50 \%$ by the fog system from 10:00 to 15:00. The other greenhouse maintained ambient RH without an artificial RH system (control). This study was conducted with controlling RH from October 3, 2019, to March 2, 2020, after transplanting strawberry plants. This experiment consisted of 3 repeats by installing three high-bench beds in each greenhouse and using each high-bench bed as one repeat, and 30 strawberry plants were planted by cultivar on one high-bench bed. The strawberry plants were supplied a nutrient solution in with water and nutrient [Research Station for Floriculture and Glasshouse Vegetables (PBG) nutrient solution; macro-elements: $\mathrm{N}: \mathrm{P}: \mathrm{K}: \mathrm{Ca}: \mathrm{Mg}: \mathrm{S} \quad=\quad$ 12.5:3.0:5.5:6.5:2.5:3.0 me $\cdot \mathrm{L}^{-1} ; \quad$ micro-elements: Fe:B:Mn:Zn:Cu:Mo = 1.12:0.27:0.55:0.46:0.05:0.05 $\mathrm{mg} \cdot \mathrm{L}^{-1}$; electrical conductivity $(\mathrm{EC})=1.0 \mathrm{dS} \cdot \mathrm{m}^{-1}$; hydrogen ion concentration $(\mathrm{pH})=5.5-6.0]$ via a drip irrigation at 2-min intervals up to five times per day. During the experiment, the temperature was controlled in the greenhouses. Ventilators were opened when the temperature was above $20^{\circ} \mathrm{C}$, but when below $17^{\circ} \mathrm{C}$ they were closed. When the temperatures were below $10^{\circ} \mathrm{C}$, the heating was turned on.

\subsection{Analysis of chlorophyll fluorescence and photosynthesis}


Chlorophyll $a$ fluorescence OJIP transient (OJIP) and photosynthesis were measured in two strawberry leaves, aged 10 and 30 days per plant between November 7 and 10, 2019.

OJIP analysis was measured with a portable fluorometer (FluorPen; Photon Systems Instruments, Drasov, Czech Republic) after 30 min of dark adaptation of the same leaf used for photosynthesis analysis from 07:00 before measuring photosynthesis.

The photosynthetic parameters such as the photosynthetic rate (PR), stomatal conductance (SC), and transpiration rate (TR) were measured, in the greenhouses, using a portable photosynthesis system (LI-6800; Licor, NE, USA). The measures were taken two times per day, on the morning (08:00 10:00) and afternoon $(14: 00 \sim 16: 00)$ of a sunny day $\left(<1,000 \mu \mathrm{mol} \cdot \mathrm{m}^{-2} \cdot \mathrm{s}^{-1}\right.$ measured by a light-emitting diode panel light installed in the chamber). In addition, to confirm the photosynthetic efficiency between temperature and RH, strawberry leaves ("Seolhyang" cultivar), between 25 and 30 days of age, were measured the photosynthesis in the morning (08:00 10:00) on February 15 and 16, 2020.

\subsection{Measurement of the survival rate and powdery mildew incidence rate}

The survival rate and the strawberry's powdery mildew incidence rate by cultivar were measured 45 days after planting in the greenhouses. The rates were calculated according to the formulas indicated below.

$$
\text { The survival rate }(\%)=\frac{\text { Number of living plants }}{\text { Number of planting plants }}
$$

$$
\text { The powdery mildew incidence rate }(\%)=\frac{\text { Number of plants with powdery spores }}{\text { Number of planting }}
$$

\subsection{Measurement of yield}

The fully ripe fruit (completely red color) was harvested at weekly intervals from January to February to confirm the fruits' yield in each treatment group.

\subsection{Experimental design and statistical analysis}

A randomized block design was used in two different greenhouses, with or without a fog system, each 
greenhouse consisted of 270 plants transplanted on three high-bench beds containing 30 plants by 3 cultivars. In this experiment, one high-bench bed installed in each greenhouse was used in one repetition. OJIP and photosynthesis were measured with nine replicates (plants) per treatment. To confirm differences between the treated group and control group, the data were analyzed using a t-test or two-way analysis of variance with Duncan's multiple range test using a significance level of $P \leq 0.05$ in SAS (SAS Institute Inc., NC, USA).

\section{Results}

\subsection{Temperature and relative humidity in the greenhouse}

The records of air temperature and RH, outside and inside the control and experimental greenhouses, are shown in Figure 2.

The ambient air temperature in October, December, and January was around $25^{\circ} \mathrm{C}, 10^{\circ} \mathrm{C}$, and $5^{\circ} \mathrm{C}$ during the daytime, and was around $10^{\circ} \mathrm{C},-3^{\circ} \mathrm{C}$, and $-4^{\circ} \mathrm{C}$ during nighttime, respectively. In all greenhouses, the air temperature during the night was maintained around $15^{\circ} \mathrm{C}$ in October and $12^{\circ} \mathrm{C}$ from December to January. However, there are differences in air temperature between the control and the greenhouse with the fog system. In the latter case, the recorded temperature was about $3^{\circ} \mathrm{C}$ to $5^{\circ} \mathrm{C}$ lower than control.

During the same period, the outside RH was around $45 \%$ during the daytime. Although, during the night was around 95\% until December and below 90\% in January. During the daytime, in the greenhouse with the fog system, the RH was maintained at $40 \%$ to $50 \%$. Meanwhile, at the control, the RH fell to less than $30 \%$.

\subsection{Photosynthesis and OJIP of strawberry leaves on initial period of cultivation}

The photosynthetic parameters taken on strawberry leaves, recorded in the morning and afternoon at the initial growth of periods, are shown in Figure 3. As the first result, all photosynthetic parameters dropped dramatically in the afternoon compared to the morning in the control and experimental greenhouses. Analyzing the PR data, the "Seolhyang" cultivar showed a significant difference according to the leaves' age in the morning. On the other hand, the "Kuemsil" cultivar showed significant differences according to the leaf's age and according to RH in the afternoon period. Also, in the afternoon, in the control groups, the PR of old leaves dropped sharply. In the afternoon of the "Seolhyang" cultivar and the morning of the "Kuemsil" cultivar, the $\mathrm{SC}$ of the young leaves of the control groups were significantly higher. The two cultivars showed TR, significantly higher in the control groups than in those in the fog treatment, especially the young leaves at control groups that were the highest.

In OJIP plotted on a logarithmic time scale, the "Kuemsil" cultivar with fog system showed a large size of fluorescence intensity when measured in the morning, whereas the "Seolhyang" cultivar was high in young 
leaves without a fog system. On the other hand, in the afternoon, the OJIP fluorescence intensity of young leaves with fog system increased in the "Seolhyang" cultivar (Figure 4).

As a result of the change in energy flux of the chloroplast membrane, in two cultivars grown under the fog system, the absorption flux per one active reaction center (ABS/RC), energy flux trapped by one active reaction center (TR/RC), and energy flux not intercepted by a reaction center (DI/RC) in the young leaves increased in the afternoon compared to the morning, and rate of electron transport by one active reaction center (ET/RC) decreased. While in the control, ABS/RC, TR/RC, and ET/RC of young leaves all decreased. The TR/RC and ET/RT in the young leaves with fog treatment, in the afternoon, were maintained higher than the control. In the old leaves of two cultivars, ABS/RC, TR/RC, ET/RC, DI/RC significantly decreased than the young leaves regardless of fog treatment. In the afternoon, the ET/RC efficiency of old leaves grown under the fog system was higher than that of control (Figure 5).

The correlation coefficient between the photosynthetic parameters and OJIP of strawberry plants with or without the fog system is shown in Figure 6. PR showed a positive correlation with SC (0.84), TR (0.67), DI/RC (0.46), and maximum quantum yield of photosystem II (PSII) photochemistry (Fv/Fm, 0.38), but a negative correlation with TR/RC $(-0.27)$ and ET/RC $(-0.28)$. SC showed a positive correlation of $99 \%$ with $\mathrm{TR}(0.83)$ and $\mathrm{DI} / \mathrm{RC}(0.46), 95 \%$ negative correlation with $\mathrm{TR} / \mathrm{RC}(-0.25)$ and $95 \%$ positive correlation with Fv/Fm (0.31), respectively. TR showed a positive correlation with DI/RC (0.42) and Fv/Fm (0.23) in parameters related to OJIP. ABS/RC does not correlate with related photosynthesis parameters. In the OJIP parameter, $\mathrm{ABS} / \mathrm{RC}, \mathrm{TR} / \mathrm{RC}$, and $\mathrm{ET} / \mathrm{RC}$ showed a positive correlation with each other, while these parameters were negatively correlated with $\mathrm{DI} / \mathrm{RC}$ and $\mathrm{Fv} / \mathrm{Fm}$.

\subsection{Survival rate and powdery mildew incidence rate of strawberry plant}

As a result of investigating the survival rate (SR) and the powdery mildew incidence rate (PMIR) for three strawberry cultivars 45 days after planting strawberry seedlings in the greenhouse, SR of "Seolhyang" and "Arihyang" cultivars was significantly increased by applying the fog system. In particular, SR of the "Seolhyang" cultivar increased by $28 \%$ or more. As well as, PMIR of the "Arihyang" cultivar grown under fog system decreased by $34 \%$ compared to the control. However, there was no difference between SR and PMIR of "Kuemsil" cultivar according to with or without fog system (Table 1).

\subsection{Yield of strawberry fruit}

In this experiment, three cultivars were tested, but the "Arihyang" cultivar was excluded. This action is related to the very severe PMIR and with the very low productivity in the control group. In January, there was 
no difference in yield of strawberry fruit for two "Seolhyang" and "Kuemsil" cultivars, while in February, the control yield was significantly higher than that of the fog treatment (Table 2).

\subsection{Photosynthesis of strawberry in six different environmental regimes}

Although SR of strawberry grown under the fog system was high, the yield was low, so photosynthesis according to temperature and RH was measured to analyze the cause of these results (Tables 3 and 4). In the temperatures $\left(15^{\circ} \mathrm{C} \sim 25^{\circ} \mathrm{C}\right)$ and $\mathrm{RH}(30 \%$ or $40 \%)$ levels of this experiment, as the temperature and $\mathrm{RH}$ increased, the PR and SC of strawberry leaves increased. PR and SC of strawberry plants measured at $40 \%$ $\mathrm{RH}$ and $25^{\circ} \mathrm{C}$ were the highest as $22.85 \mu \mathrm{mol} \cdot \mathrm{m}^{-2} \cdot \mathrm{s}^{-1}$ and $346.8 \mathrm{mmol} \cdot \mathrm{m}^{-2} \cdot \mathrm{s}^{-1}$, respectively, while strawberry plants measured at $30 \% \mathrm{RH}$ and $15^{\circ} \mathrm{C}$ were the lowest at $12.13 \mu \mathrm{mol} \cdot \mathrm{m}^{-2} \cdot \mathrm{s}^{-1}$ and $131.0 \mathrm{mmol} \cdot \mathrm{m}^{-2} \cdot \mathrm{s}^{-1}$. The highest PR and TR values were, respectively, $88 \%$ and 164\% higher than those of the lowest value. On the other hand, the TR of strawberry leaves increased according to increasing temperature and decreasing RH (Table 3). RH had a significant effect on the PR and SC of strawberry plants, and the temperature had a significant influence on the TR as well as PR and SC of strawberry plants (Table 4). However, the interaction between temperature and RH on photosynthesis of strawberry plants was not significant.

\section{Discussion}

The fog system in greenhouses was used to control RH in this experiment. When spraying fog, not only $\mathrm{RH}$ in the greenhouse but also the temperature changed significantly (Figure 2). The temperature decreased, and RH increased in the greenhouse during the daytime according to fog treatment. The fog treatment was effective for SR and PMIR of strawberry plants by providing the environment in the greenhouse at the initial growth stage of the strawberry plant with a suitable temperature and $\mathrm{RH}$ for strawberry growth (Table 1). It is known that the growth of strawberry plants is optimal when the temperature is $30^{\circ} \mathrm{C}[20]$, which supports our findings that the decrement in greenhouse temperature due to fog treatment increases SR of strawberry plants. Also, PMIR of the "Arihyang" cultivar, high incidence of powdery mildew, was relatively higher in control than in the fog treatment during the initial stages of growth. Strawberry plants grown under control are considered to have been weakened compared to treatment with fog because at the early growth stage, they were affected by high temperatures close to $40^{\circ} \mathrm{C}$ and $30 \%$ of low RH conditions during the daytime.

Thus, the temperature and RH are very important elements that interact with each other as environmental factors for growing crops in a greenhouse. The temperature is reported to play a major role in enzyme activity involved in starch biosynthesis and gene expression [21]. In addition, RH is known to affect the growth of crops, influencing photosynthesis by acting on the opening and closing of leaf stomata $[5,8]$. Photosynthesis 
occurs in two stages, the light and dark reactions, positively correlated, and to increase photosynthesis efficiency, both must have good activity. To analyze the photo-physiological response according to the environment, the PR related to the dark reaction and the chlorophyll fluorescence reaction related to the light reaction of photosynthesis are used as major analysis tools $[14,22]$. Also, it is known that the phenotypic expression is very diverse because of the large genetic variation in octoploid strawberry [23]. In this study, when the photo-physiological responses of strawberry plants at different temperature and RH were measured using these two photosynthetic analysis tool, differences between cultivars were widely revealed. The RH influence on the PR value of the "Seolhyang" cultivar was small, but the difference according to the leaf's age was large (Figure 3A). On the other hand, the PR value of the "Kuemsil" cultivar was found to be affected by RH in the afternoon, and the difference in the leaves' age was not significant (Figure 3D). Nevertheless, PR of the old leaves of both cultivars grown under control dropped sharply than fog treatment. Our results are similar to the reports that PR of strawberry plants is increased under high RH conditions than low RH [14]. It was reported that RH conditions of $65 \%$ to $75 \%$ are suitable for strawberry growth in the summer season [24], and tomato is also known to be beneficial for photosynthesis by appropriately increasing RH in a greenhouse [25]. It was found that the energy flux on the chloroplast membrane of two strawberry cultivars grown under the greenhouse maintaining high $\mathrm{RH}$ due to the fog treatment was more effective in the afternoon than that of control (Figure 5). These results indicate a positive effect on strawberries' growth due to the photosynthetic activity in which the synthesis of NADPH and ATP is induced through the light reaction. The present study results are in agreement with previous reports that state that the OJIP parameters of strawberry grown in high RH in the growth chamber are higher than in low RH [14]. The activity of PSII is easily recovered under heat stress below $45^{\circ} \mathrm{C}$, but the damage of PSII (irreversible decrease of photochemical activity) is significantly increased as always the most vulnerable part of the photosynthetic machinery [26, 27, 28]. In this experiment, it was assumed that the PSII activity of strawberries grown in the fog treatment was good, not by increasing the RH through fog spraying in the initial growth stage but also by controlling $5^{\circ} \mathrm{C}$ below about $40^{\circ} \mathrm{C}$ concerning the control temperature (Figure 2A and 5). The young leaves showed a sensitive response according to changes in temperature and $\mathrm{RH}$ environment due to fog treatment than that of old leaves, and the fluorescence intensity of young leaves grown under fog treatment did not decrease and remained steadily in the afternoon (Figure 4). Previous reports show that the chlorophyll a fluorescence of plant leaves decreases rapidly under heat stress and drought stress, resulting in a dramatic drop in the OJIP curve [26, 29]. In this study, we consider that the high temperature and low RH of the greenhouse during the day of the initial growth period influenced the photosynthetic system of strawberry plants, having a negative effect on strawberry growth by reducing carbon fixation metabolism activity. Also, PR, SC, TR/RC, ET/RC, and DI/RC, which 
represent the light reaction and the dark reaction of photosynthesis, were significantly correlated with each other, according to environmental conditions (Figure 6). Therefore, these photosynthetic parameters are an excellent tool to analyze the physiological response of crops grown in a greenhouse.

However, in the measurement of strawberry yield in control and fog treatment in January and February, it was found that the yield of strawberry plants grown under fog treatment decreased to the control plants. The results of these months are related to the daytime temperature in the registered greenhouse, in which it fell to values that negatively affect the growth of strawberry plants. Due to the fog treatment in winter, the temperature registered in the greenhouse with the fog system was significantly lower than that of the control (Figure 2). The analysis of the results of photosynthesis parameters in different environmental conditions, reveals that with low $\mathrm{RH}$ and temperature below $20^{\circ} \mathrm{C}$, the photosynthetic efficiency deteriorates rapidly (Table 3 and 4). RH also affected photosynthesis, but the effect of temperature was remarkably higher than RH. The low temperature is a risk factor to strawberry plants due to be reduced PR [30], in which the strawberry PR is better when the temperature was $29^{\circ} \mathrm{C}$, whit the PR difference not significant at $19^{\circ} \mathrm{C}$ to $31^{\circ} \mathrm{C}$ [12]. In line with our investigation, an earlier study [31] showed that the strawberry fruit yield was rapidly reduced as the temperature decreased from $20^{\circ} \mathrm{C}$ to $15^{\circ} \mathrm{C}$, in a greenhouse. After all, when using the fog system to manage $\mathrm{RH}$ in a greenhouse, it is considered to be advantageous to use it within a range that does not deviate from the temperature range suitable for strawberry cultivation.

\section{Conclusions}

Our results demonstrate how the growth of strawberry plants depends on the changes in temperature and RH conditions. When placed in a stressful environment-related to temperature and RH, the efficiency of photosynthesis drops sharply. Therefore, properly controlling the temperature and RH in strawberry cultivation in a greenhouse is an important management method. From the analysis of the present study results, it was confirmed that the effect of the temperature surpasses the RH effect on strawberry growth in a greenhouse. In conclusion, we intend to provide an environmental management algorithm for the temperature and RH in the strawberry cultivation of the greenhouse using a fog system. In conclusion, according to the algorithm presented in this study (Figure 7), if the temperature in a greenhouse is controlled above $20^{\circ} \mathrm{C}$ and the RH does not fall below $40 \%$ using a fog system, these parameters are expected to be advantageous in the strawberry cultivation with increased fruit production.

Author Contributions: HY Choi and NJ Kang designed the experiments and wrote the manuscript. 
Funding: This study was carried out with the financial assistance from the Kongju National University and the Rural Development Administration, Republic of Korea (Project No. PJ01383405).

Acknowledgments: The authors would like to thank DW Kim and TK Lee for their assistance related photosynthetic measurement in this study.

Conflicts of Interest: The authors declare no conflict of interest.

\section{References}

1. Dusenge, M.E.; Duarte, A.G.; Way, D.A. Plant carbon metabolism and climate change: elevated $\mathrm{CO}_{2}$ and temperature impacts on photosynthesis, photorespiration and respiration. New Phytol. 2019, 221, 32-49.

2. Khan, F.A.; Kurklu, A.; Ghafoor, A.; Ali, Q.; Umair, M.; Shahzaib, A. A review on hydroponic greenhouse cultivation for sustainable agriculture. Inter. J. Agri. Environ. Food Sci. 2018, 2, 59-66.

3. Tang, Y.; Ma, X.; Li, M.; Wang, Y. The effect of temperature and light on strawberry production in a solar greenhouse. Sol. Energy 2020, 195, 318-328.

4. Suzuki, M.; Umeda, H.; Matsuo, S.; Kawasaki, Y.; Ahn, D.; Hamamoto, H.; Iwasaki, Y. Effects of relative humidity and nutrient supply on growth and nutrient uptake in greenhouse tomato production. Sci. Horti. 2015, 187, 44-49.

5. Aliniaeifard, S.; Meeteren, U.V. Stomatal characteristics and desiccation response of leaves of cut chrysanthemum (Chrysanthemum morifolium) flowers grown at high air humditiy. Sci. Horti. 2016, 205, 84-89.

6. Singh, H.; Kumar, P.; Chaudhari, S.; Edelstein, M. Tomato grafting: a global perspective. HortScience 2017, $52,1328-1336$.

7. Zucchi, P.; Martinatti, P.; Marcolla, E.; Genovese, M.; Pantezzi, T. Influence of air humidity enrichment under high tunnel conditions on some quantitative and qualitative parameters of strawberry fruit. Acta Hort. 2016, 1117, 279-284.

8. Fanourakis, D.; Giday, H.; Hyldgaard, B.; Bouranis, D.; Körner, O.; Ottosen, C.O. Low air humidity during cultivation promotes stomatal closure ability in rose. Eur. J. Hortic. Sci. 2019, 84, 245-252.

9. Rodrigues, C.R.F.; Silveira, J.A.G.; Viégas, R.A.; Moura, R.M.; Aragão, R.M.; Silva, E.N. Combined effects of high relative humidity and $\mathrm{K}+$ supply mitigates damage caused by salt stress on growth, photosynthesis and ion homeostasis in J. curcas plants. Agric. Water Manag. 2016, 163, 255-262.

10. Kaushal, R.; Ghosh, P. Stable oxygen and carbon isotopic composition of rice (Oryza sativa L.) grains as 
recorder of relative humidity. J. Geophysical Res. 2018, 123, 423-439.

11. Ministry of Agriculture, Food and Rural Affairs in Korea. Agriculture, food and rural affairs statistics yearbook. 2015, http://library.mafra.go.kr/skyblueimage/2513.pdf.

12. Jun, H.; Jung, H.; Imai, K. Gas exchange characteristics of a leading cultivar of Korean strawberry (Fragaria $\times$ ananassa, 'Sulhyang'). Sci. Hort. 2017, 221, 10-15.

13. Shabbir, A.; Mao, H.; Ullah, I.; Buttar, N.A.; Ajmal, M.; Lakhiar, I.A. Effects of drip irrigation emitter density with various irrigation levels on physiological parameters, root, yield, and quality of cherry tomato. Agronomy 2020, 10, 1685.

14. Choi, H.G.; Jeong, H.J. Comparison of chlorophyll fluorescence and photosynthesis of two strawberry cultivars in response to relative humidity. Horti. Sci. Technol. 2020, 38, 66-77.

15. Choi, M.H.; Jang, M.S.; Jun, H.J. Effect of humidification treatment on growth of Korean strawberry $($ Fragaria $\times$ ananassa) cultivars Seolhayng and Kuemsil grown in greenhouse. Horticultural Abstracts in KSHS. 2019, 5, 186. http://www.dbpia.co.kr/journal/articleDetail?nodeId=NODE08740357.

16. Zushi, K.; Matsuzoe, N. Using of chlorophyll a fluorescence OJIP transients for sensing salt stress in the leaves and fruits of tomato. Sci. Horti. 2017, 219, 216-221.

17. Tang, X.; An, B.; Cao, D.; Xu, R.; Wang, S.; Zhang, Z.; Liu X.; Sun, X. Improving photosynthetic capacity, alleviating photosynthetic inhibition and oxidative stress under low temperature stress with exogenous hydrogen sulfide in blueberry seedlings. Front. Plant Sci. 2020, 11, 108.

18. Zavefer, A.; González-Solís, A.; Palacios-Bahena, S.; Saucedo-García, M.; Aquino, C.T; Vázquez-Santana, S.; King-Díaz, B.; Gavilanes-Ruiz, M. Organized disassembly of photosynthesis during programmed cell death mediated by long chain bases. Sci. Rep. 2020, 10, 10360.

19. Gao, M.; Chang, X.; Yang, Y.; Song, Z. Foliar graphene oxide treatment increases photosynthetic capacity and reduces oxidative stress in cadmium-stressed lettuce. Plant Physiol. Biochem. 2020, 154, 287-294.

20. Kadir, S.; Sidhu, G. Strawberry (Fragaria $\times$ ananassa Duch.) growth and productivity as affected by temperature. HortiScience 2006, 41, 1423-1430.

21. Lu, H.; Hu, Y.; Wang, C.; Liu, W.; Ma, G.; Han, Q.; Ma, D. Effects of high temperature and drought stress on the expression of gene encoding enzymes and the activity of key enzymes involved in starch biosynthesis in wheat grains. Front. Plant Sci. 2019, 10, 1414.

22. Kaiser, E.; Kromdijk, J.; Harbinson, J.; Heuvelink, E.; Marcelis, L.F.M. Photosynthetic induction and its diffusional, carboxylation and electron transport processes as affected by $\mathrm{CO}_{2}$ partial pressure, temperature, air humidity and blue irradiance. Ann. Bot. 2017, 119, 191-205.

23. Gezan, S.; Osorio, L.F.; Verma, S.; Whitaker, V.M. An experimental validation of genomic selection in 
octoploid strawberry. Hortic. Res. 2017, 4, 16070.

24. Lieten, P. The effect of humidity on the performance of greenhouse grown strawberry. Acta Hortic. 2002, $567,101$.

25. Suzuki, M.; Umeda, H.; Matsuo, S.; Kawasaki, Y.; Ahn, D.; Hamamoto, H.; Iwasaki, Y. Effects of relative humidity and nutrient supply on growth and nutrient uptake in greenhouse tomato production. Sci. Horti. 2015, 187, 44-49.

26. Rout, G.R.; Das, A.B. (Eds). Molecular stress physiology of plants; Springer, New Delhi, 2013.

27. Sharkey, T.D. Effects of moderate heat stress on photosynthesis: importance of thylakoid reactions, rubisco deactivation, reactive oxygen species, and themotolerance provided by isoprene. Plant Cell Environ. 2005, $28,269-277$.

28. Allakhverdiev, S.I.; Kreslavski, V.D.; Klimov, V.V.; Los, D.A.; Carpentier, R.; Mohanty, P. Heat stress: and overview of molecular responses in photosynthesis. Photosynth. Res. 2008, 98, 541-550.

29. Brestic, M.; Zivcak, M.; Kalaji, H.M.; Carpentier, R.; Allakhverdiev, S.I. Photosystem II thermostability in situ: environmentally induced acclimation and genotype specific reactions in Triticum aestivum L. Plant Physio. Biochem. 2012, 57, 93-105.

30. Xu, C.; Wang, M.T.; Yang, Z.Q.; Zheng, Q.T. Low temperature and low irradiation induced irreversible damage of strawberry seedlings. Photosynthetica 2020, 58, 156-164.

31. Lee, G.B.; Choe, Y.U.; Park, E.J.; Wang, Z.; Li, M.; Park, Y.H.; Choi, Y.W.; Kang, N.J.; Kang, J.S. Influence of abnormally low temperatures on growth, yield, and biologically active compounds of strawberry. J. Environ. Sci. Inter. 2017, 26, 381-392. 


\section{Tables}

Table 1 . The survival rate and the powdery mildew incidence rate of the strawberries, 45 days after greenhouse planting, according to with or without fog systems.

\begin{tabular}{ccccccc}
\hline & \multicolumn{2}{c}{ Seolhyang } & \multicolumn{2}{c}{ Kuemsil } & \multicolumn{2}{c}{ Arihyang } \\
\cline { 2 - 6 } Treatment & SR (\%) & PMIR (\%) & SR (\%) & PMIR (\%) & SR (\%) & PMIR (\%) \\
\cline { 2 - 6 } AF & $89.1 \pm 2.4$ & $2.2 \pm 1.8$ & $92.2 \pm 2.4$ & $1.3 \pm 1.5$ & $93.7 \pm 2.5$ & $22.1 \pm 8.2$ \\
NF & $61.0 \pm 5.7$ & $3.1 . \pm 1.0$ & $90.8 \pm 4.3$ & $2.6 \pm 2.0$ & $90.6 \pm 0.5$ & $56.5 \pm 7.7$ \\
T-test & $* *$ & NS & NS & NS & $*$ & $*$ \\
\hline
\end{tabular}

NS, *, **Non-significant or significant at $P<0.05$ or 0.01 by t-test, respectively $(n=30)$. SR: survival rate; PMIR: powdery mildew incidence rate; AF: with fog system; NF: without fog system (control).

Table 2. The yield of strawberry fruits, from January to February, according to with or without fog systems.

\begin{tabular}{|c|c|c|c|c|c|c|}
\hline \multirow{3}{*}{ Treatment } & \multicolumn{6}{|c|}{ Yield (g/plant) } \\
\hline & \multicolumn{2}{|c|}{ January } & \multicolumn{2}{|c|}{ February } & \multicolumn{2}{|c|}{ Total } \\
\hline & Seolhyang & Kuemsil & Seolhyang & Kuemsil & Seolhyang & Kuemsil \\
\hline $\mathrm{AF}$ & 51.2 & 48.4 & 71.1 & 60.7 & 122.3 & 109.1 \\
\hline NF & 53.3 & 46.6 & 89.2 & 72.3 & 142.5 & 118.9 \\
\hline T-test & NS & NS & $* *$ & $* *$ & $* *$ & $* *$ \\
\hline
\end{tabular}


Table 3. The photosynthetic parameters of strawberry leaves in six different environmental regimes, consisting of two relative humidity levels and three temperature levels.

\begin{tabular}{cccc}
\hline Treatment & $\begin{array}{c}\text { PR } \\
\left(\mu \mathrm{mol} \cdot \mathrm{m}^{-2} \cdot \mathrm{s}^{-1}\right)\end{array}$ & $\begin{array}{c}\text { SC } \\
\left(\mathrm{mmol} \cdot \mathrm{m}^{-2} \cdot \mathrm{s}^{-1}\right)\end{array}$ & $\begin{array}{c}\text { TR } \\
\left(\mathrm{mmol} \cdot \mathrm{m}^{-2} \cdot \mathrm{s}^{-1}\right)\end{array}$ \\
\hline FRH15 & $17.09 \pm 2.16 \mathrm{c}$ & $203.7 \pm 93.9 \mathrm{bc}$ & $2.07 \pm 0.80 \mathrm{c}^{\mathrm{z}}$ \\
FRH20 & $19.51 \pm 0.49 \mathrm{ab}$ & $286.2 \pm 24.6 \mathrm{ab}$ & $3.11 \pm 0.35 \mathrm{bc}$ \\
FRH25 & $22.85 \pm 2.12 \mathrm{a}$ & $346.8 \pm 56.9 \mathrm{a}$ & $4.35 \pm 0.16 \mathrm{ab}$ \\
TRH15 & $12.13 \pm 0.52 \mathrm{~d}$ & $131.0 \pm 16.9 \mathrm{c}$ & $2.14 \pm 0.19 \mathrm{c}$ \\
TRH20 & $18.26 \pm 1.41 \mathrm{~b}$ & $241.6 \pm 48.0 \mathrm{ab}$ & $4.28 \pm 0.88 \mathrm{ab}$ \\
TRH25 & $20.30 \pm 3.12 \mathrm{ab}$ & $290.9 \pm 83.7 \mathrm{ab}$ & $5.11 \pm 1.00 \mathrm{a}$ \\
\hline
\end{tabular}

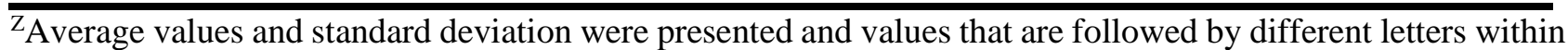
a columns are significantly different (DMRT, $P<0.05 . n=9$ ). PR: photosynthetic rate; SC: stomatal conductance; TR: transpiration rate; FRH: $40 \%$ relative humidity; TRH: $30 \%$ relative humidity; $15: 15^{\circ} \mathrm{C} ; 20$ : $2^{\circ} \mathrm{C} ; 25: 25^{\circ} \mathrm{C}$.

Table 4. The effect of relative humidity and temperature and between them on photosynthetic parameters of strawberry leaves in six different environmental regimes, consisting of two relative humidity levels and three temperature levels.

\begin{tabular}{ccccccccc}
\hline \multirow{2}{*}{$\begin{array}{c}\text { Photosynthetic } \\
\text { parameter }\end{array}$} & \multicolumn{3}{c}{ Relative humidity $(\%)$} & \multicolumn{3}{c}{ Temperature $\left({ }^{\circ} \mathrm{C}\right)$} & & Interaction \\
\cline { 2 - 9 } & FRH & TRH & $P$ value & 15 & 20 & 25 & $P$ value & $P$ value \\
\hline $\begin{array}{c}\mathrm{PR} \\
\left(\mu \mathrm{molCO} \mathrm{m}^{-2} \cdot \mathrm{s}^{-1}\right)\end{array}$ & 19.81 & 16.89 & 0.007 & 14.61 & 18.89 & 21.57 & 0.000 & 0.264 \\
$\begin{array}{c}\mathrm{SC} \\
\left(\mathrm{mmolH} \mathrm{O}_{2} \cdot \mathrm{m}^{-2} \cdot \mathrm{s}^{-1}\right)\end{array}$ & 283 & 226 & 0.047 & 176 & 263 & 325 & 0.003 & 0.923 \\
$\begin{array}{c}\mathrm{TR} \\
\left(\mathrm{mmolH}_{2} \mathrm{O} \cdot \mathrm{m}^{-2} \cdot \mathrm{s}^{-1}\right)\end{array}$ & 3.84 & 3.17 & 0.152 & 2.10 & 3.69 & 4.73 & 0.001 & 0.597 \\
\hline
\end{tabular}

$P$ values were determined by two-way ANOVA. Tr: transpiration rate; PR: photosynthetic rate; $S C$ : stomatal conductance; TR: transpiration rate; FRH: 40\% relative humidity; TRH: 30\% relative humidity. 


\section{Figure}

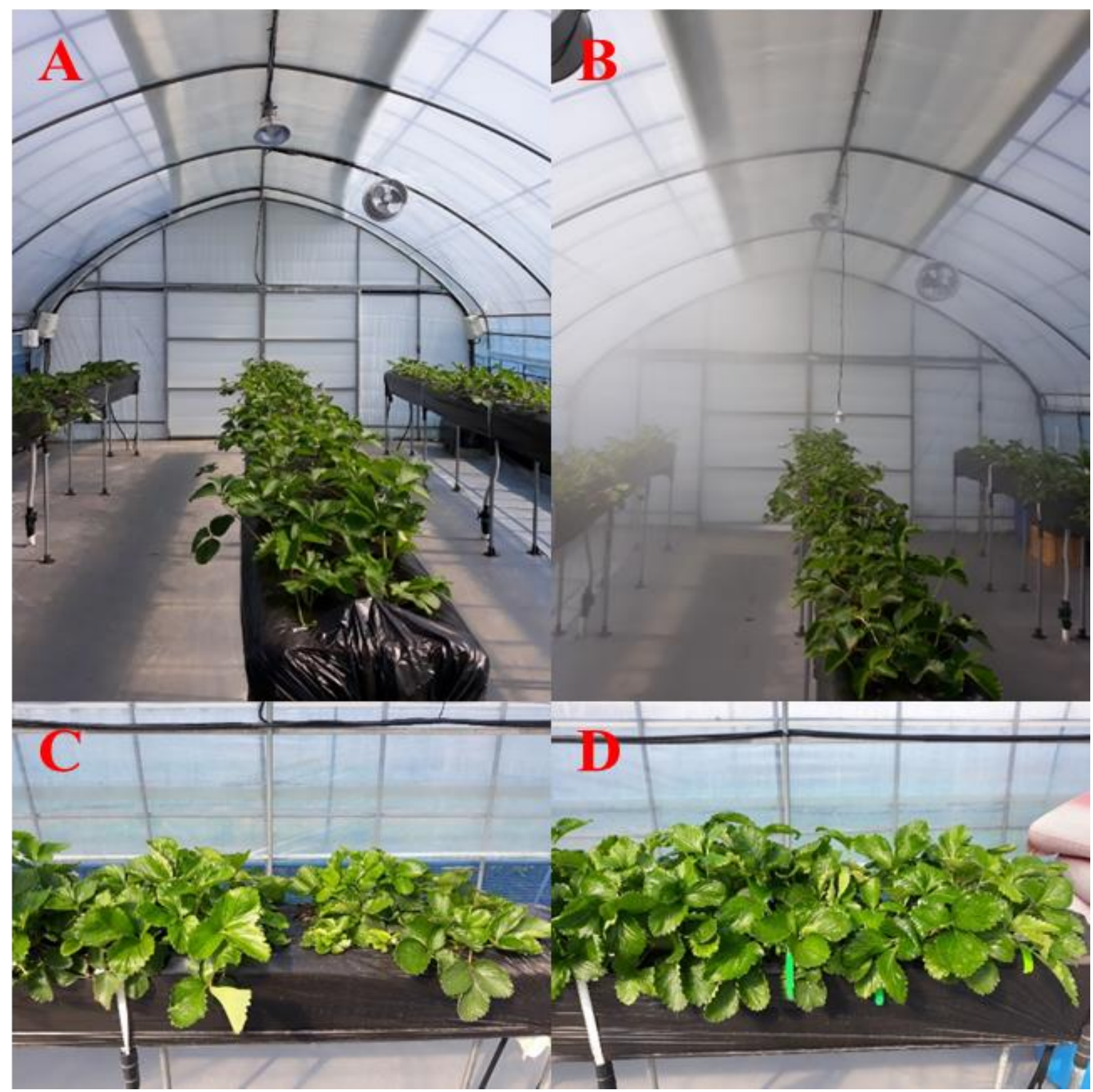

Figure 1. The strawberry plants cultivation under conditions with or without fog spray system. A: without fog spray system (control); B: with fog spray system; C: strawberry plants cultivation in control; D: strawberry plants cultivation with fog system. 

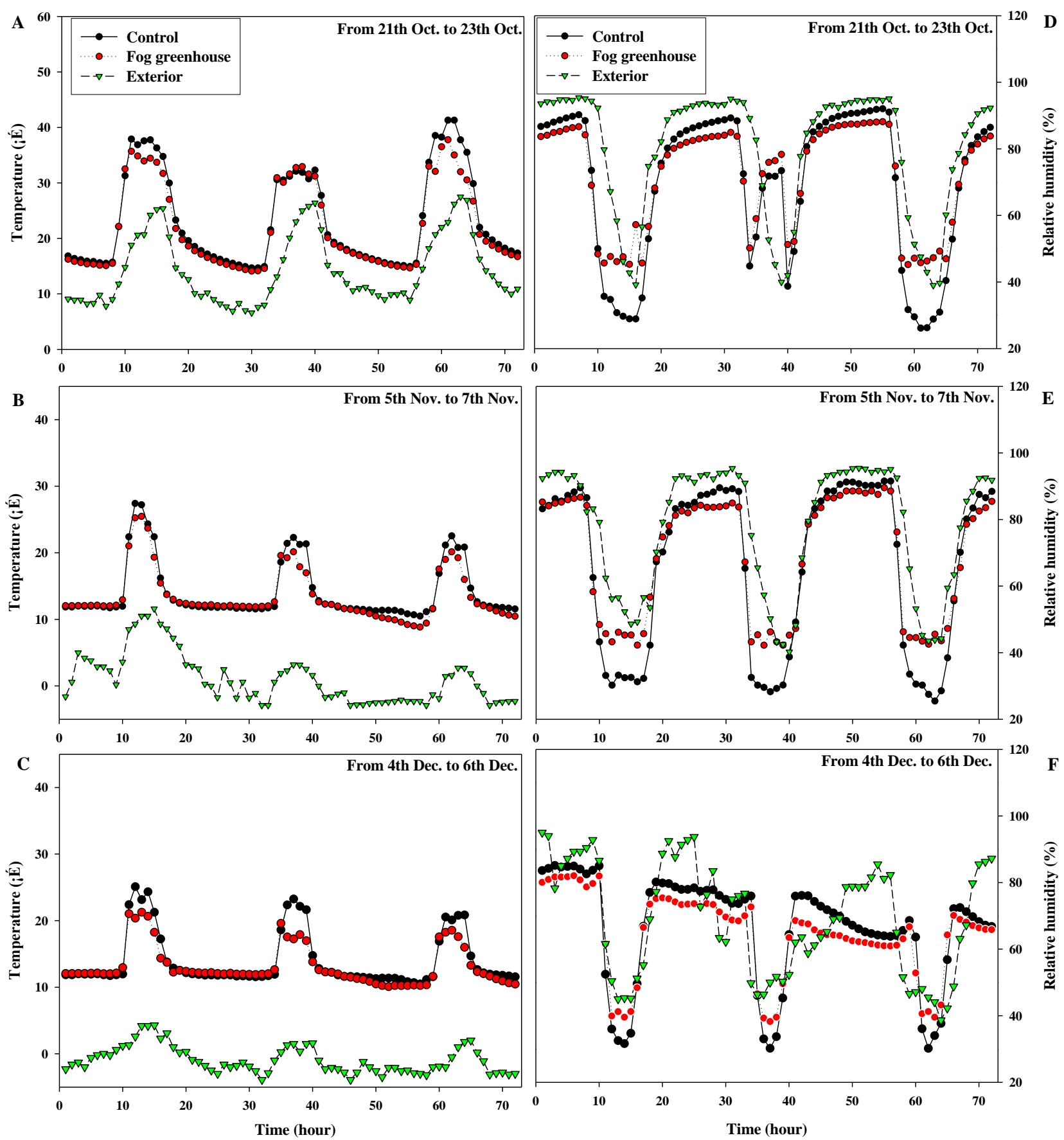

Figure 2. Outside and inside environmental conditions of the greenhouses with or without (control) a fog system. 

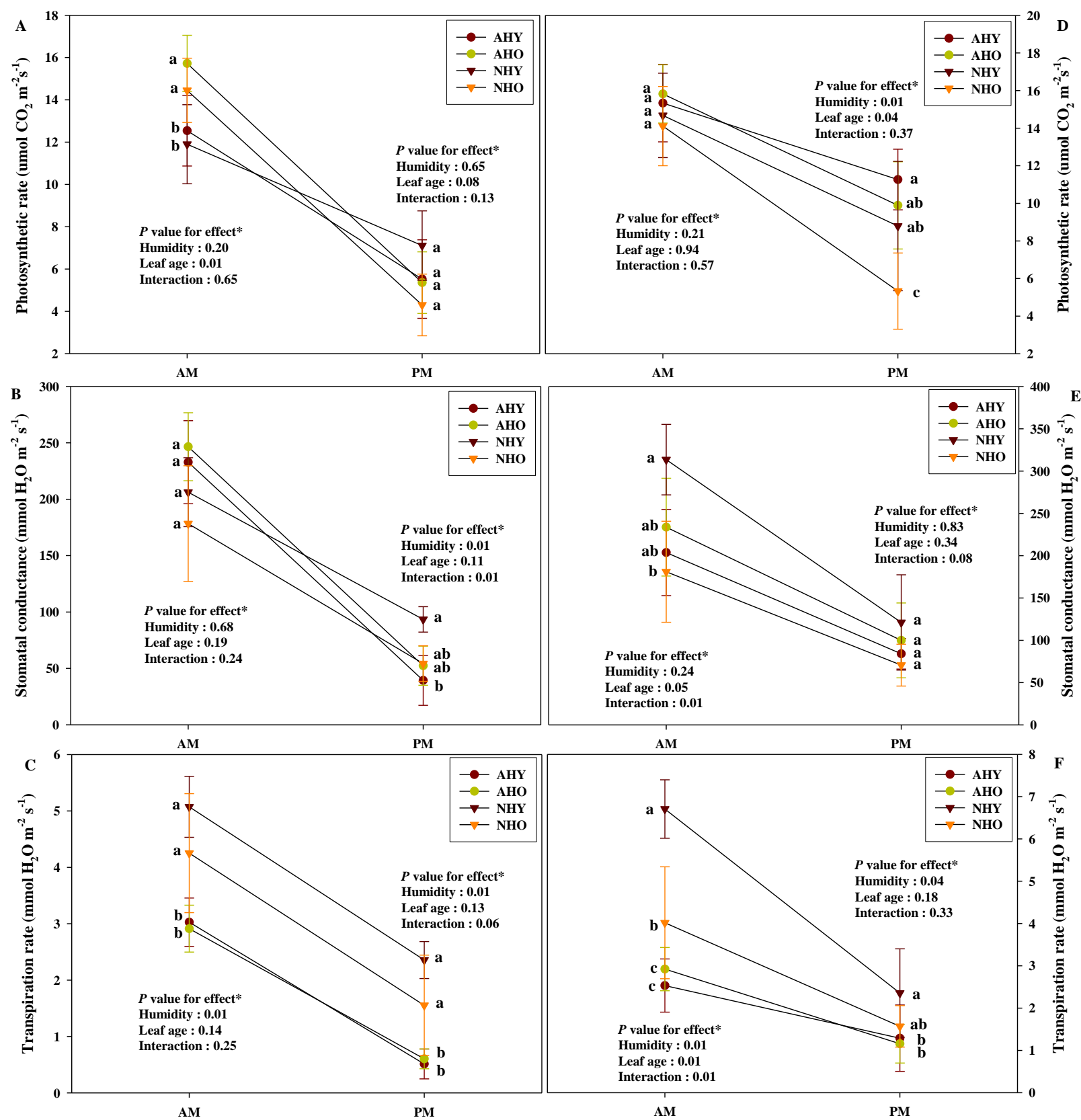

Figure 3. Photosynthetic parameters on morning and afternoon of two strawberry cultivars according to with or without fog system. A, B, and C: "Seolhyang" cultivar; D, E, and F: "Kuemsil" cultivar; AFY: 10 days old leaves after fully unfold with fog system; AFO: 30 days old leaves after fully unfold with fog system; NFY: 10 days old leaves after fully unfold without fog system; NFO: 30 days old leaves after fully unfold without fog system. ${ }^{*} P$ values were determined by two-way ANOVA. Values marked with different lowercase letters are significantly different by Duncan's multiple range test $(P<0.05)$. 

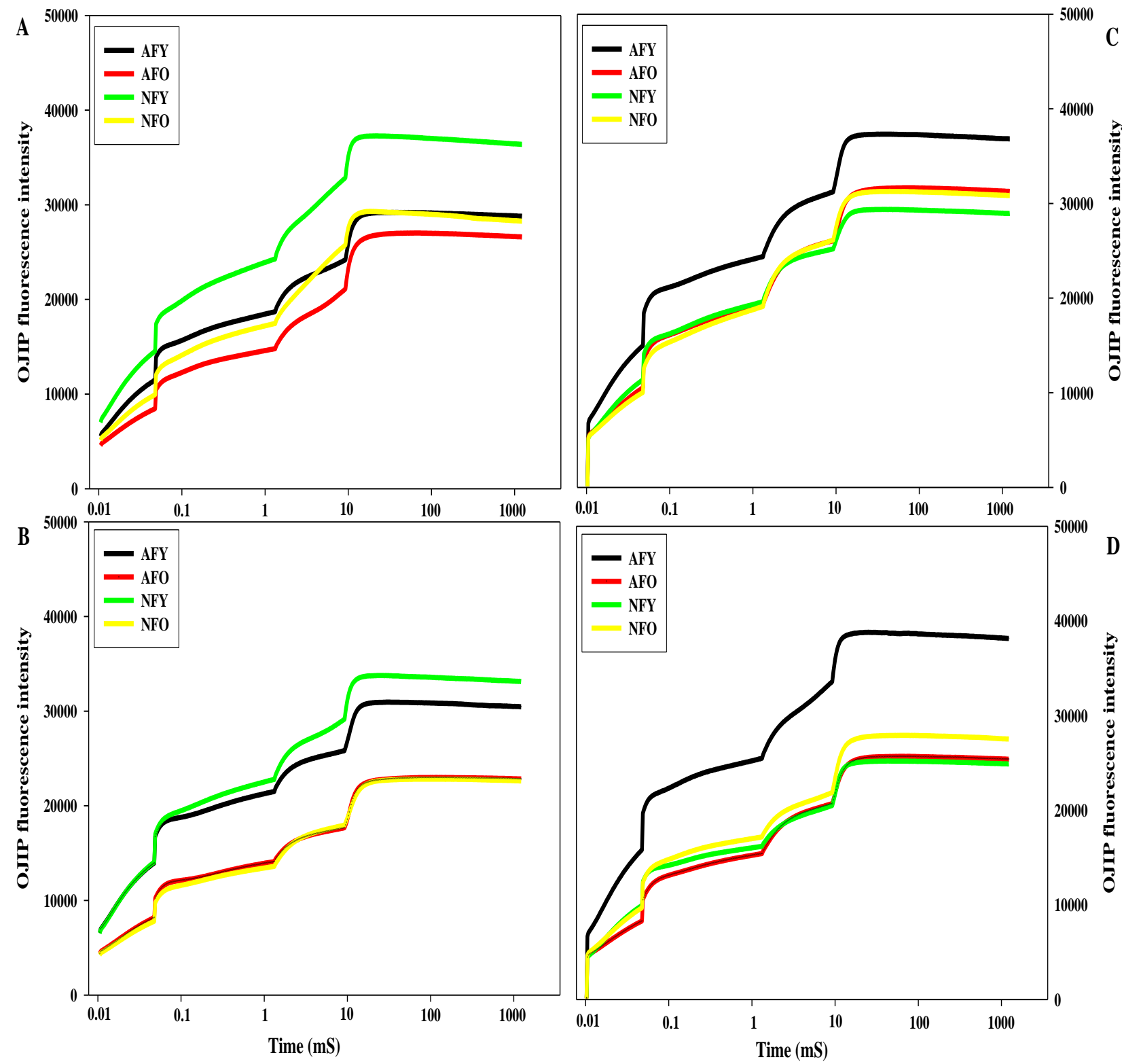

Figure 4. OJIP Chlorophyll a fluorescence transients plotted on a logarithmic time scale measured in morning and afternoon of two strawberry cultivars according to with or without fog system. A and B: "Seolhyang" cultivar; C and D: "Kuemsil" cultivar; A and C: analyzed in the morning; B and D: analyzed in the afternoon; AFY: 10 days old leaves after fully unfold with fog system; AFO: 30 days old leaves after fully unfold with fog system; NFY: 10 days old leaves after fully unfold without fog system; NFO: 30 days old leaves after fully unfold without fog system. 


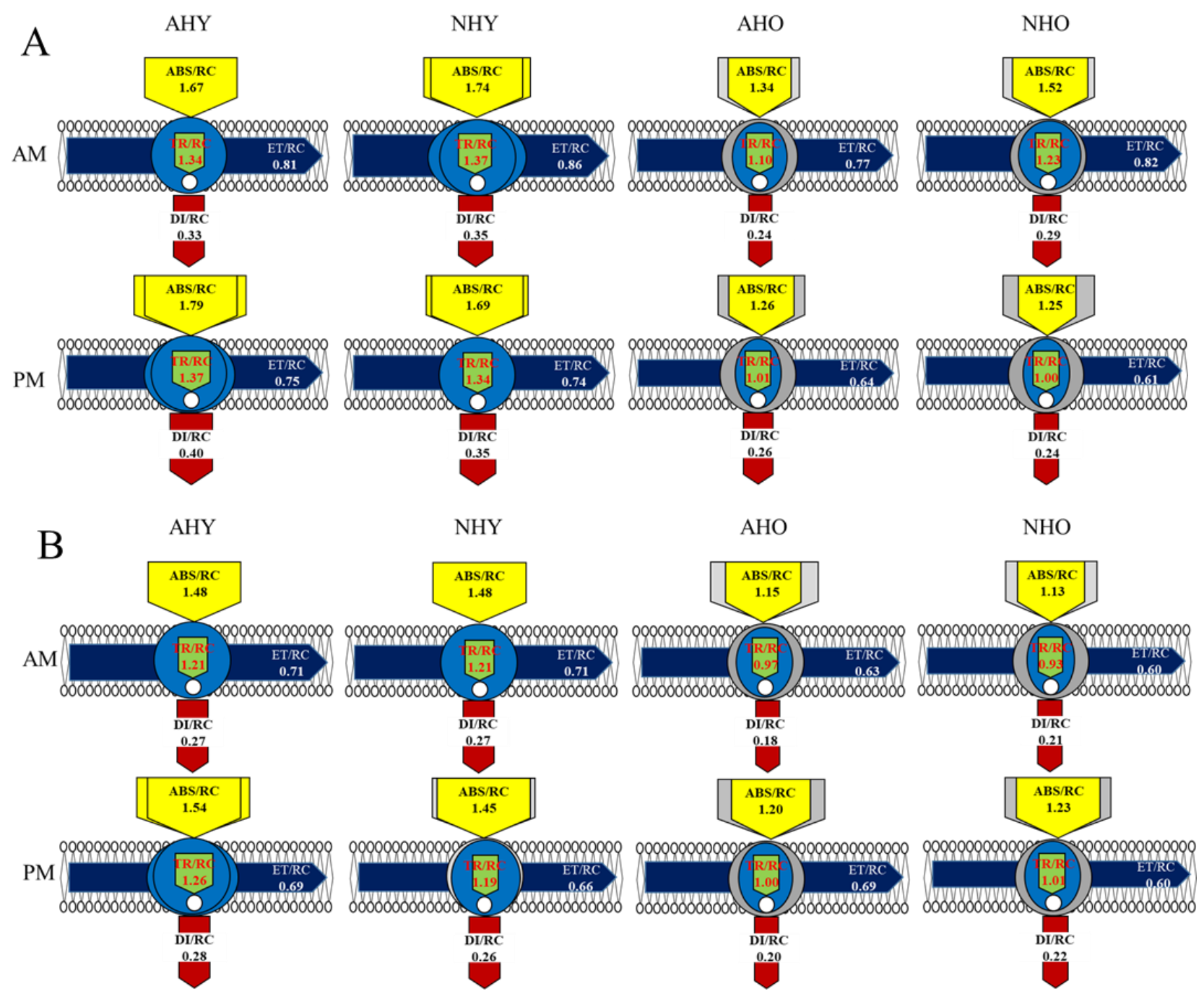

Figure 5. Models of energy flux on chloroplast membrane, in the morning and the afternoon, of two strawberry cultivars according to with or without fog system. A: "Seolhyang" cultivar; B: "Kuemsil" cultivar; AFY: 10 days old leaves after fully unfold with fog system; AFO: 30 days old leaves after fully unfold with fog system; NFY: 10 days old leaves after fully unfold without fog system; NFO: 30 days old leaves after fully unfold without fog system; AM: morning; PM; afternoon; ABS/RC: absorption flux per one active reaction center; TR/RC: energy flux trapped by one active reaction center; ET/RC: rate of electron transport by one active reaction center; DI/RC: energy flux not intercepted by a reaction center. 


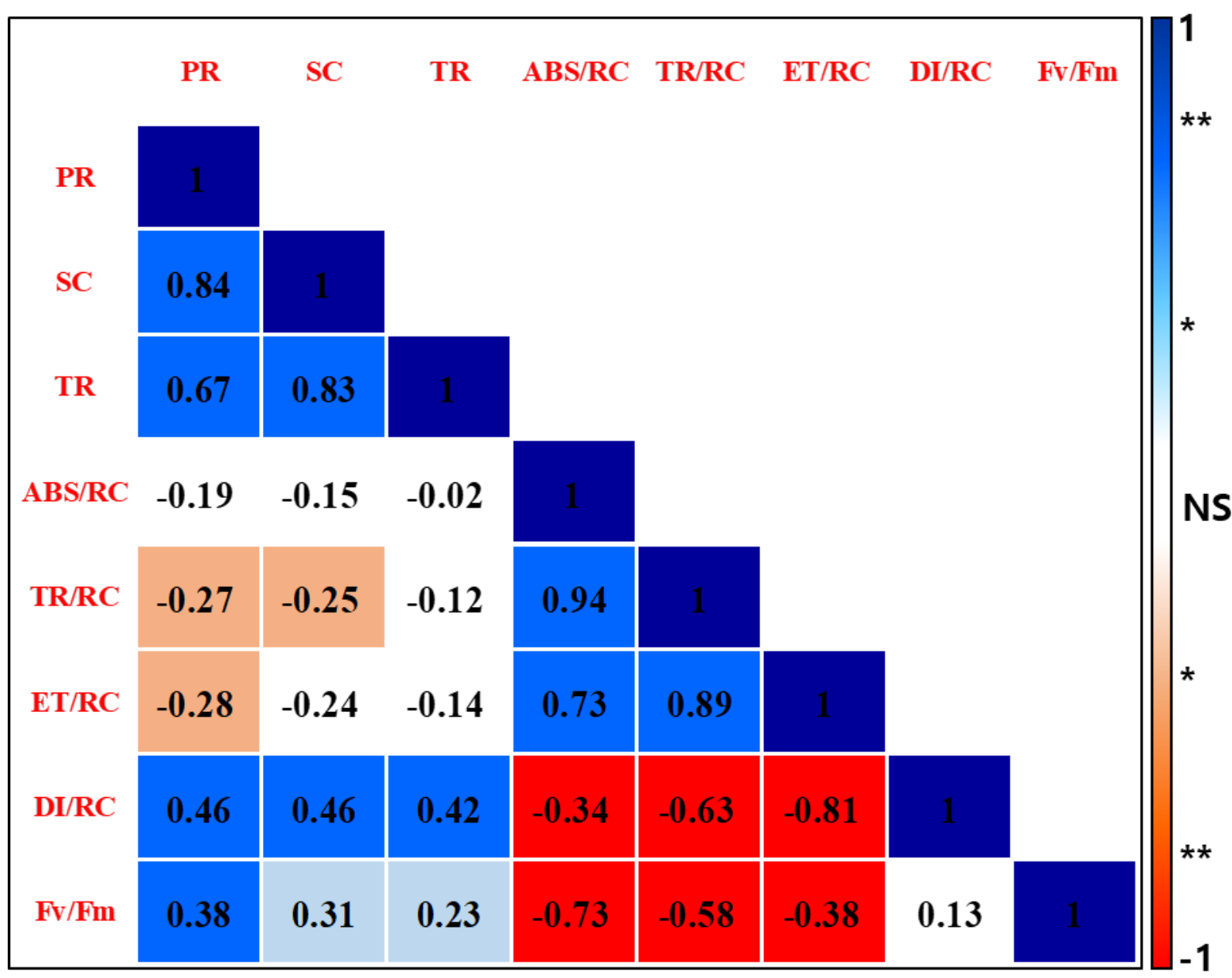

Figure 6. Correlation coefficients between photosynthetic parameters and OJIP chlorophyll a fluorescence transient parameters of strawberry (Fragaria $\times$ ananassa) plants according to with or without fog system. Significant differences are shown at the $5 \%$ and $1 \%$ levels $(n=64)$, respectively, using Pearson correlation coefficients. ${ }^{* *}$ Dark blue box: positive correlation of $99 \% ; * *$ Red box: negative correlation of $99 \% ;{ }^{*}$ Light blue box: positive correlation of 95\%; *Pink box: negative correlation of 95\%; ${ }^{\text {NS}}$ White box: non-significant correlation. PR: photosynthetic rate; SC: stomatal conductance; TR: transpiration rate; ABS/RC: absorption flux per one active reaction center; TR/RC: energy flux trapped by one active reaction center; $\mathrm{ET} / \mathrm{RC}$ : rate of electron transport by one active reaction center; DI/RC: energy flux not intercepted by a reaction center; $\mathrm{Fv} / \mathrm{Fm}$ : maximum quantum yield of photosystem II photochemistry. 


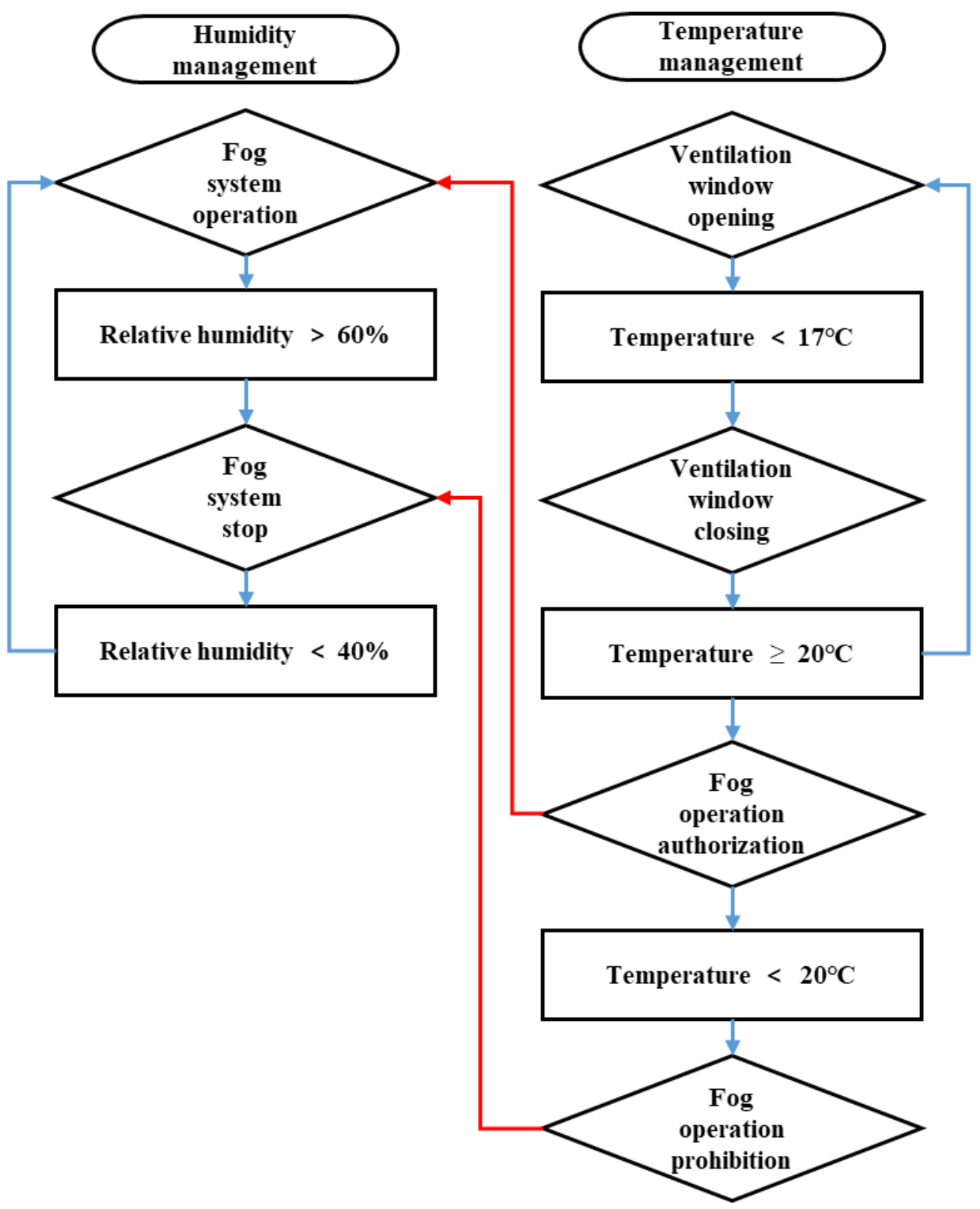

Figure 7. Algorithm for controlling the temperature and relative humidity using a fog system based on photosynthesis results shown in Table 3 during the daytime of strawberry cultivation periods in a greenhouse. 